\title{
Penggunaan Instant Messenger dan Komunikasi Interpersonal Remaja
}

\author{
Primada Qurrota Ayun \\ Departemen Ilmu Komunikasi, FISIP Undip \\ email : primadaqa.ayu@gmail.com
}

\begin{abstract}
Interpersonal communication should ideally in face to face, until the achievement of intimate communication. Instant messenger makes interpersonal communication easier and more efficient. However, it also resulted in less effective communication to occur, because it only uses text messaging as a means to convey a message so frequent miscommunication. This study wanted to see how the use of instant messenger among teenagers in interpersonal communication. The theory used in this study is a Computer Mediated Communication, Ecology Media and Interpersonal Intimacy. The method used in this research is phenomenology. The results of this study indicate that the instant messenger is a medium that is considered to be practical and easy to communicate interpersonally with family, friends, and lovers. Interpersonal communication process through instant messenger can not reach the stage of intimate relationship, because of interactions that occur frequently experienced miscommunication due to an incorrect perception. Interpersonal communication is more effective if it is done face to face. Teens when communicating via instant messenger, tend not to believe and to tell the truth.
\end{abstract}

Keywords : interpersonal communication, instant messenger, intimate relationship, teens

\section{PENDAHULUAN}

Perkembangan information communication and technology (ICT) di Indonesia, berkembang cukup pesat. ICT membuat struktur pemahaman kita untuk mengakses informasi dan pesan menjadi lebih berkembangan. Perkembangan ICT saat ini menyebabkan semua jenis media yang lama dan baru, konvensional dan interaktif menjadi sebuah media yang konvergen. Keberadaan ICT, telah mempermudah masyarakat dalam mencari, memperoleh, dan mengolah informasi.

Perkembangan ini juga berdampak terhadap perubahan pola komunikasi interpersonal individu. Dalam perkembangannya komunikasi interpersonal saat ini tidak harus dilakukan secara tatap muka. Hal yang lebih menarik, individu lebih suka berlama-lama di depan gadgetnya ketimbang berkomunikasi dengan orang lain. Fitur di dalam sebuah gadget mempermudah seseorang untuk melakukan percakan secara interpersonal kepada individu lain melalui instant messenger.

Instant messenger merupakan sebuah fitur yang saat ini banyak digunakan oleh masyarakat untuk bertukar pesan. 


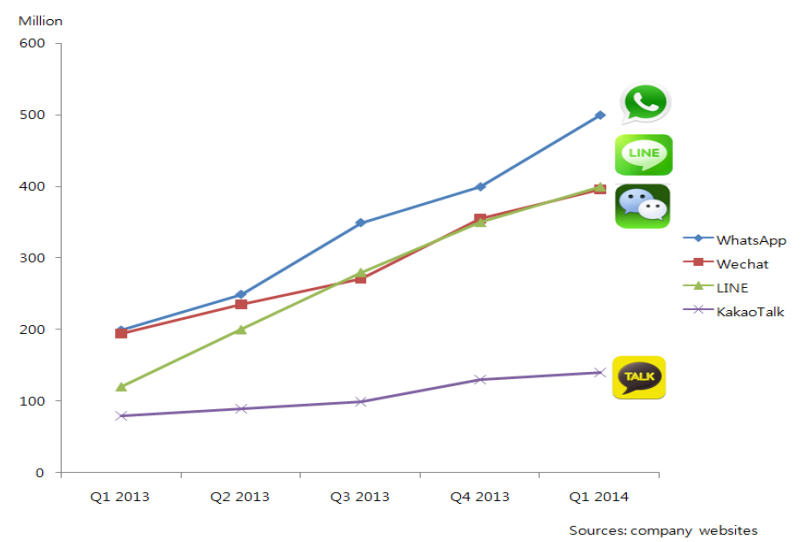

Gambar 1.

Perkembangan Pengguna Instant messenger

(sumber : Park dkk, 2014)

Dari grafik diatas bisa dilihat bagaimana kenaikan pengguna instant messengers. Di Indonesia, survei yang dilakukan oleh UNICEF dengan Kominfo, The Berkman Center for Internet and Society, dan Harvard University mengenai penggunaan dan tingkah laku internet para remaja, menunjukkan bahwa setidaknya 30 juta orang remaja di Indonesia yang mengakses internet secara regular (Lukman, 2014).

Hasil penelitian Global Web Index (GWI), perusahaan riset global khusus untuk perilaku konsumen online (Alia dan Amal, 2014) menemukan bahwa di Indonesia pengguna aplikasi mobile messaging telah meningkat 45 persen sejak 2013. "Salah satu yang mendorong pertumbuhan ini adalah penggunaan perangkat mobile. Di mana kami temukan, pengguna di sini, 86 persen sudah memiliki smartphone," kata Jason Mander, Head if Trends GlobalWebIndex, di Kuningan City, Selasa 25 November 2014. Riset itu mengungkap aplikasi messaging terpopuler di Indonesia yaitu WhatsApp (54 persen), Facebook Messenger (45 persen), WeChat (29 persen), Skype (28 persen), Line (26 persen), Kakao Talk (19 persen) dan lainnya.

Keberadaan instan messenger secara tidak langsung mengubah bagaimana pola komunikasi interpersonal. Teknologi tersebut dianggap sebagai sebuah sarana untuk mempermudah komunikasi interpersonal. Tetapi, komunikasi interpersonal yang efektif adalah komunikasi yang terjadi diantara dua individu dimana terdapat kesamaan di dalam pemaknaan sebuah pesan antara komunikator dan komunikan. Kemudian adanya komunikasi interpersonal juga diharapkan mampu terciptanya sebuah intimacy. Penelitian ini ingin melihat bagaimana komunikasi interpersonal remaja melalui penggunaan instant messenger.

\section{KERANGKA TEORITIS}

\section{Computer Mediated Communication}

New media atau media baru menurut Flew (2004:9) adalah penggabungan dari communicators networks, computing/information technology, dan content (media). Penggabungan ketiga hal ini menghasilkan sebuah media yang konvergen. Fungsi dari konvergensi media oleh Miles (Flew, 2004:10) adalah sebagai informasi dan media yang meningkatkan proses pemikiran berdasarkan sistem teknologi berbasis komputer dan membawa pengguna media melintasi jaringan komunikasi. Sedangkan tujuan dari konvergensi adalah pencapaian suatu tujuan yaitu pengelolaan konten, baik berupa informasi, gambar, audio, dan lain-lain, agar dapat diakses masuk dalam jenis teknologi apapun sehingga dapat dikonsumsi oleh satu jenis atau berbagai jenis media. Ciri dari media yang konvergen ada tiga, yaitu : 
- Computing/Information Technology

Adalah sebuah teknologi pengolahan dan pendistribusian informasi melalui komputer dan perangkatnya.

- Content

Konten pada media baru memperluas mediasi (remediasi) yang memunculkan realitas media.

- Communication Network

Lingkar kausalitas dari konten yang interaktif, konten interaktif menyatukan pengakses dan terjadinya budaya partisipasi.

CMC berkaitan dengan cepatnya invensi dan luasnya inovasi dalam teknologi komunikasi. Penggabungan komputer dengan telekomunikasi ini melahirkan sebuah fenomena yang mengubah konfigurasi modal komunikasi konvensional ke era digital. CMC memiliki ciri yaitu suatu teknologi yang bertujuan untuk berkomunikasi bukan hanya untuk pengolahan info, tetapi juga terdapat proses interaksi sosial.

Salah satu bentuk kemajuan ICT adalah adanya media sosial. Karakteristik media sosial menurut Nasrullah (2015: 16-34), yaitu ;

- Jaringan (network)

Media sosial memiliki karakteristik sebagai jaringan. Jaringan inti terbentuk melalui jaringan informasi yang terjadi diantara para pengguna media sosial tersebut. Secara tidak langsung jaringan ini membentuk komunitas, kemudian memunculkan nilai-nilai baru di dalam masyarakat.

- Informasi

Informasi menjadi entitas yang penting di dalam media sosial. Karena pengguna media siber menkreasikan representasi identitasnya, memproduksi konten, dan melakukan proses komunikasi berdasarkan informasi. Bahkan informasi menjadi semacam komoditas di dalam masyarakat informasi.

- Arsip

Bagi pengguna media siber, arsip menjadi sebuah karakter yang menjelaskan bahwa informasi telah tersimpan dan bisa diakses kapan pun dan melalui perangkat apapun.

- Interaksi

Interaksi merupakan sebuah bentuk hubungan yang terjadi di dalam media siber. Bagaimana individu saling memberikan komentar dan menanggapi pesan yang disampaikan.

- Simulasi sosial

Dalam menggunakan media siber, interaksi yang terjadi memang menggambarkan bahkan mirip dengan realitas. Namun sebenarnya interaksi yang terjadi merupakan simulasi dengan kata lain berbeda dengan kenyataan yang ada.

- Konten oleh pengguna

Dalam media siber, konten oleh pengguna adalah bahwa isi dari media siber sepenuhnya milik dan berdasarkan kontribusi dari pengguna atau pemilik akun.

- Penyebaran

Media siber tidak hanya menghasilkan konten yang diproduki dan dikonsumsi oleh penggunanya tetapi juga melakukan proses pendistribusian sekaligus pengembangan oleh penggunanya.

\section{Technological Determinism}

Setiap jenis teknologi, melahirkan lingkungan teknologi. Lingkungan teknologi ini secara tidak langsung merubah kebudayaan, norma-norma sosial, pola-pola interaksi, dan organisasi-organisasi masyarakat. Ungkapan ini secara tidak langsung menjelaskan mengenai ungkapan McLuhan mengenai hubungan antara teknologi, media, dan masyarakat atau yang sering disebut dengan tehnological determinsm, yaitu paham bahwa teknologi bersifat determinan atau menentukan dalam membentuk kehidupan manusia. 
Dalam gagasan tersebut, McLuhan (Morissan dkk, 2010: 31) menyatakan bahwa teknologi berpengaruh sangat besar dalam masyarakat, dengan kata lain kehidupan masyarakat juga dipengaruhi oleh teknologi. Teknologi komunikasi menyebabkan terjadinya perubahan budaya dan pola komunikasi yang ada. Teknologi media telah meciptakan resolusi di tengah masyarakat, karena masyarakat sudah sangat terpengaruh dengan teknologi dan tatanan masyarakat pun terbentuk berdasarkan pada kemampuan masyarakat dalam menggunakan teknologi.

Adanya persepsi kita terhadap media dan bagaimana kita menafsirkan media menjadikan inti gagasan dari teori ekologi media. Terdapat tiga asumsi penting dalam teori ekologi media yang dikemukakan oleh McLuhan (West \& Turner, 2007), yaitu ;

- Media mempengaruhi setiap perbuatan atau tindakan dalam masyarakat.

Asumsi ini menekankan bahwa manusia tidak dapat lepas dari media. Media merupakan sebuah hal yang penting, bahkan menembus ke dalam kehidupan manusia yang paling dalam. Keberadaan media memberikan pengaruh dalam kehidupan manusia dan masyarakat.

- Media memperbaiki persepsi dan mengelola pengalaman

Asumsi kedua ini mencoba menjelaskan bahwa dalam kehidupan manusia, baik secara langsung maupun tidak langsung dipengaruhi oleh keberadaan media. Media memiliki peran yang besar dalam membentuk dan mempengaruhi pandangan kita dalam melihat dunia.

- Media mengikat dunia bersama-sama

Asumsi ketiga dari teori ekologi media menyebutkan bahwa media mengikat dunia bersama-sama. Dalam hal ini McLuhan menggunakan istilah global village dimana media mengikat dunia menjadi satu sistem politik, ekonomi, sosial, dan budaya global. Media mampu menyatukan dunia ke dalam sebuah budaya populer dan global.

Dari ketiga asumsi diatas, kita bisa melihat bahwa keberadaan media sangat berkaitan erat dengan masyarakat.

Saat ini keberadaan media telah mempengaruhi setiap tindakan individu, kemudian secara tidak langsung media juga memberikan pengaruh terhadap cara pandang kita terhadap sesuatu, dan media mengikat dunia secara bersama-sama. Global village, menunjukkan bahwa kita hidup dalam sebuah masyarakat yang global dan menerima informasi dengan sangat cepat. Media telah mampu menyatukan dunia kedalam sebuah desa, dan secara sosial mengelola masyarakat yang ada di dunia.

\section{Interpersonal Communication}

Salah satu dari hal yang penting di dalam hubungan interpersonal adalah tercapainya komunikasi yang intim. Beebee dkk (2005: 260), mengatakan bahwa interpersonal intimacy is the degree to which a person's sense of self is accepted and confirmed by another person in a relationship. Terdapat beberapa aspek bagaimana hubungan seseorang dapat mencapai level intim, yaitu;

1. Merasa dekat,

2. Bercerita mengenai apa yang dirasakan dan dipikirkan,

3. Saling mengapresiasi,

4. Saling mendukung satu dengan yang lain, 
5. Memiliki kedekatan emosional,

6. Unconditional support,

7. Keterbukaan dan kejujuran,

8. Kasih sayang dan kehangatan.

Hubungan yang intim tidak hanya terjadi pada sepasang kekasih saja, tetapi dapat dilihat melalui bagaimana seseorang melihat orang lain, kemudian mereka saling memberikan respon yang positif.

Tiga tipe hubungan yang termasuk kedalam komunikasi interpersonal yang intim menurut Beebee dkk (2005: 273-283) adalah;

- Friends. Merupakan sebuah hubungan yang terjadi pada suatu keadaan antara orang dengan orang lain, yang saling bercerita mengenai pengalaman mereka. Seorang teman adalah yang seperti kita, dan kita seperti mereka, dimana kita bercerita tentang hal yang baik dan buruk. Terdapat beberapa aspek yang menunjukkan sebuah hubungan pertemanan : keterbukaan diri, kejujuran, kesamaan, ego reinforcement, saling menghargai, respect, saling membantu, saling memberi masukan, percaya, dan berempati.

- Lovers : Romantic Relationship. Merupakan bagian yang tertinggi dalam hubungan komunikasi intim. Dalam komunikasi ini terdapat tiga dimensi ; intimacy (kepercayaan, komitmen, dan passion), komitmen (loyalitas, kesetiaan, menjadikan prioritas, dan saling membutuhkan) dan passion (kegembiraan, ketertarikan seksual, dan keinginan bersama).

- Family Relationship. Hubungan keluarga dilihat dari pengasuhan, pemberian dukungan, mengembangkan konsep diri, memberikan pengarah mengenai masa depan dan merupakan komunikasi yang kompleks. Dalam hal ini yang termasuk kedalam hubungan keluarga adalah hubungan antara anak dan orang tua, serta hubungan dengan kakak dan adik (saudara kandung).

\section{METODOLOGI PENELITIAN}

Analisis terhadap data kualitatif mengacu pada metode fenomenologi dari Von Eckartsberg (dalam Moustakas, 1994: 15-16). Langkah-langkah yang digunakan dalam penelitian fenomenologi ini adalah sebagai berikut :

1. Permasalahan dan perumusan pertanyaan penelitian. Peneliti berusaha untuk menggambarkan fokus penelitian dengan merumuskan pertanyaan dengan cara tertentu. Pertanyaan dari penelitian meliputi beberapa aspek komunikasi interpersonal yaitu ;

- Merasa dekat,

- Bercerita mengenai apa yang dirasakan dan dipikirkan,

- Saling mengapresiasi,

- Saling mendukung satu dengan yang lain,

- Memiliki kedekatan emosional,

- Unconditional support,

- Keterbukaan dan kejujuran,

- Kasih sayang dan kehangatan.

2. Data yang menghasilkan situasi, yaitu teks pengalaman kehidupan. Peneliti membuat narasi yang bersifat deskriptif yaitu menjabarkan hasil wawancara yang telah dilakukan.

3. Analisis data, berupa eksplikasi dan interpretasi. Setelah semua data terkumpul berdasarkan hasil wawancara, maka langkah terakhir yang harus dilakukan oleh peneliti adalah membaca dan meneliti dengan cermat data hasil wawancara untuk mengungkapkan konfigurasi makna, baik struktur maupun bagaimana makna tersebut diciptakan. 


\section{HASIL PENELITIAN DAN PEMBAHASAN}

Komunikasi interpersonal merupakan sebuah bentuk pertukaran pesan yang terjadi antara seorang individu dengan individu yang lainnya. Seiring dengan perkembangan jaman, bentuk komunikasi interpersonal pada saat ini dapat dilakukan melalui pertukaran teks atau gambar. Instant messenger, merupakan salah satu medium yang menjadi tempat pertukaran pesan tersebut terjadi.

McLuhan (Griffin, 2003) menyatakan mengenai hubungan antara teknologi, media, dan masyarakat atau yang sering disebut dengan tehnological determinsm, yaitu paham bahwa teknologi bersifat determinan atau menentukan dalam membentuk kehidupan manusia. Adanya instant messenger mengubah bentuk pola komunikasi interpersonal individu kepada keluarga, teman/ sahabat, dan kekasih.

Pengaruh dari perkembangan teknologi telah menjadikan perubahan bahasa dalam media siber. Cyrstal (dalam Nasrullah, 2015: 82) menjelaskan bahwa bahasa internet merupakan medium keempat setelah bahasa tulis, bahasa bicara, dan bahasa tanda. Atau bisa dikatakan bahwa pengaruh dari teknologi pada akhirnya memunculkan apa yang disebut dengan ikon emosi (emoticon).

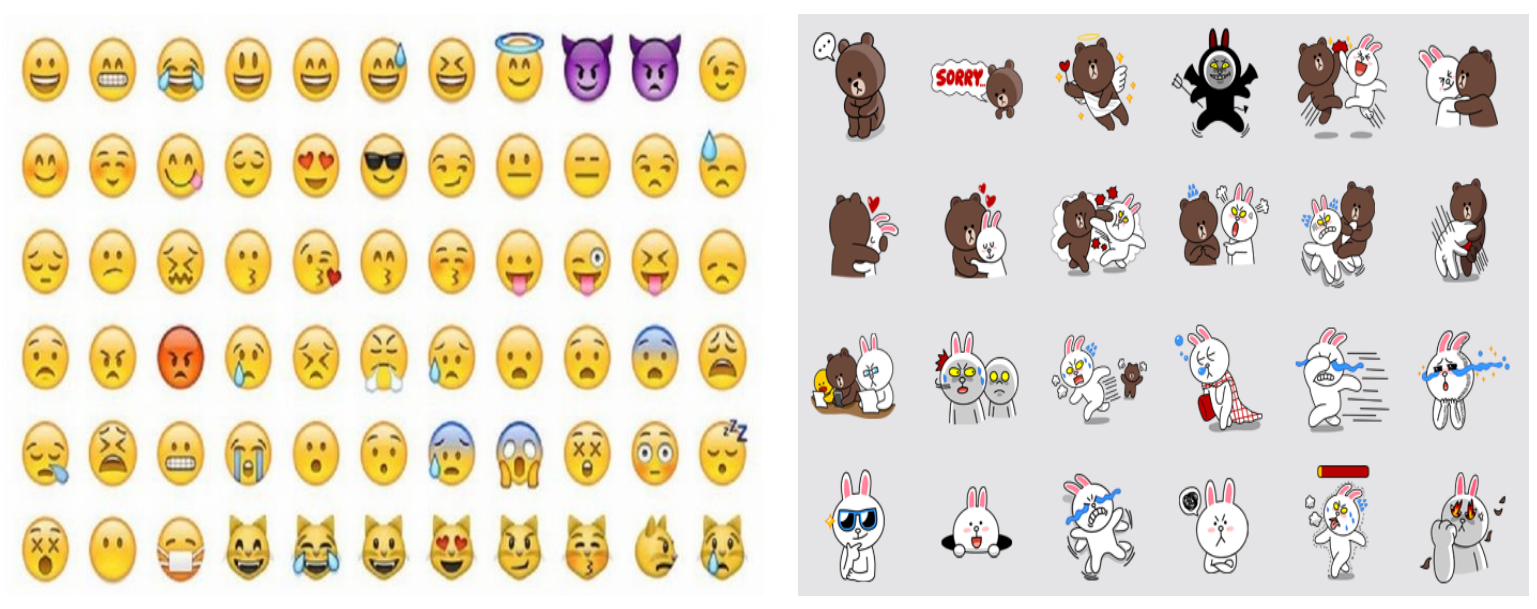

Gambar 2. Emoticon Whatsapp dan Sticker Line

Ikon-ikon ini muncul sebagai bentuk dari emosi pengguna pada saat berkomunikasi melalui instant messenger. Teks di dalam media siber dibagi menjadi dua bentuk, yaitu netspeak dan netlingo. Thurlow et al (2004 : 124 - 125), menjelaskan bahwa netspeak adalah pembicaraan yang seolah - olah adalah bahasa tertulis. Sedangkan netlingo sebagai bentuk penulisan teks yang seolah - olah berbicara. Teks yang ditulis dalam media siber menjadi suatu bahasa yang seolah - olah mewakili ucapan atau suara beserta intonasinya dalam percakapan keseharian.

Hasil dari penelitian ini menunjukkan bahwa dengan adanya emoticon untuk berkomunikasi, membuat komunikasi melalui instant messenger menjadi lebih efektif dari pada hanya berkomunikasi melalui teks. Emoticon yang ada dijadikan sebagai bentuk pengungkapan perasaan.

DeVito (1997: 26) mengemukakan terdapat komponen-komponen penting dalam komunikasi antarmanusia secara universal, yang perlu diperhatikan oleh setiap komunikator, yaitu; konteks (lingkungan) komunikasi, sumber-penerima, enkoding-dekoding, kompetensi komunikasi, pesan dan saluran, umpan balik, gangguan, dan efek komunikasi. Dengan adanya perkembangan teknologi, komunikasi interpersonal dapat dilakukan menggunakan medium yaitu instant messenger. 
Salah satu dari karakteristik yang terdapat dalam media siber, khususnya di dalam instant messenger, yaitu interactivity. Gane \& Beer (2008: 97) menjelaskan bahwa interaksi menjadi pembeda antara media lama dan media baru, terdapat beberapa konsep yang dapat menjelaskan mengenai interactivity, yaitu;

- Interaksi merupakan sebuah struktur yang menghubungkan khalayak maupun teknologinya yang dibangun dari perangkat keras maupun perangkat lunak dari berbagai sistem media.

- Interaksi memerlukan individu sebagai human agency.

- Interaksi menunjukkan sebuah konsep tentang komunikasi yang terjadi antara pengguna yang termediasi oleh media baru dan memberikan kemungkinan - kemungkinan baru yang selama ini terjadi dalam komunikasi interpersonal.

- Interaksi juga bisa diartikan sebagai konsep yang menghapus sekat atau atasan ruang dan waktu, dengan kata lain komunikasi secara virtual dapat terjadi kapanpun.

Komunikasi interpersonal melalui instant messenger menunjukkan bahwa saat ini bentuk komunikasi antarpribadi dapat dilakukan dari jarak jauh. Salah satu dari hal yang penting di dalam hubungan interpersonal adalah tercapainya komunikasi yang intim.

Komunikasi interpersonal dengan teman, dijelaskan menurut Beebee dkk (2005: 273) adalah suatu hubungan yang terjadi pada suatu keadaan antara orang dengan orang lain, yang saling bercerita mengenai pengalaman mereka. Seorang teman adalah yang seperti kita, dan kita seperti mereka, dimana kita bercerita tentang hal yang baik dan buruk. Hasil dari penelitian ini menunjukkan bahwa pada saat para informan melakukan komunikasi melalui instant messenger, mereka bercerita dan mendapatkan dukungan dari teman mereka.

Tetapi komunikasi yang intim susah dibangun di dalam komunikasi ini dikarenakan para informan mengatakan bahwa mereka tidak berkata jujur dan tidak terbuka pada saat berkomunikasi dengan teman mereka. Mereka pun tidak percaya dengan apa yang disampaikan oleh teman mereka, alasan dari para informan adalah mereka tidak bisa melihat gesture dari lawan bicara mereka apakah jujur atau berbohong.

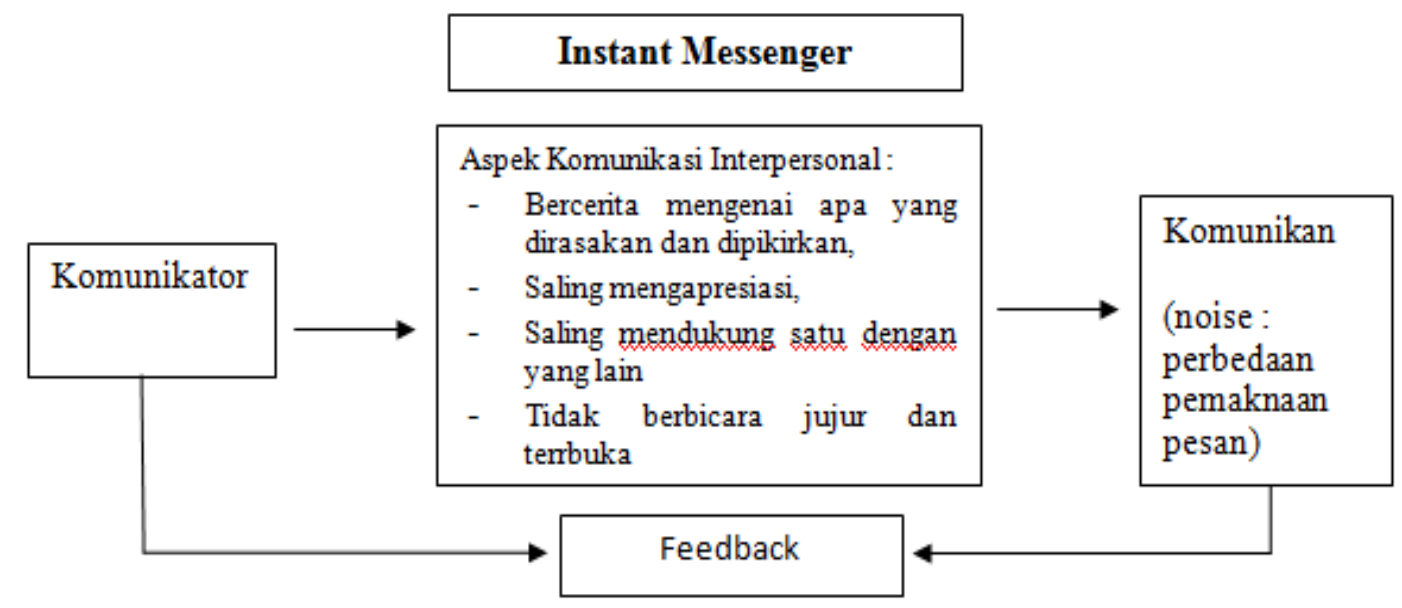

\section{Gambar 3. Komunikasi Interpersonal dengan Teman melalui Instant Messenger}

Romantic relationship yang terjadi melalui instant messenger, hanya mencakup beberapa aspek saja. Para informan mengakui dengan adanya kedekatan, saling mengapresiasi, dan saling mendukung antara pasangan. Tetapi para informan mengakui bahwa tidak merasakan kedekatan emosional, kehangatan serta kasih sayang dari kekasih. 


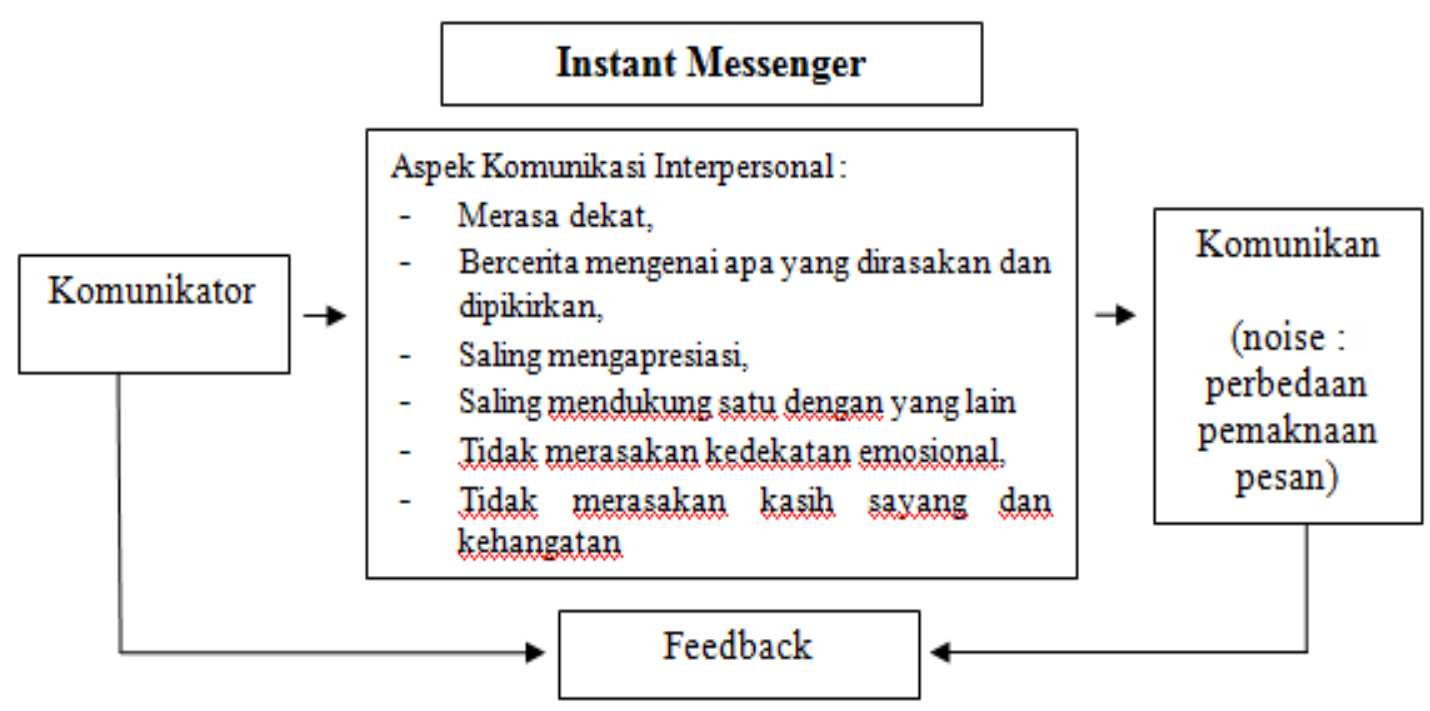

Gambar 4. Komunikasi Interpersonal dengan Kekasih melalui Instant Messenger

Komunikasi keluarga yang terjadi melalui instant messenger menunjukkan bahwa informan cenderung tidak terbuka dan jujur terhadap keluarga mereka. Namun disisi lain keberadaan instant messenger, menjadi sarana untuk keluarga memberikan dukungan kepada para informan. Para informan merasakan kasih sayang dari keluarga melalui percakapan di instant messenger.

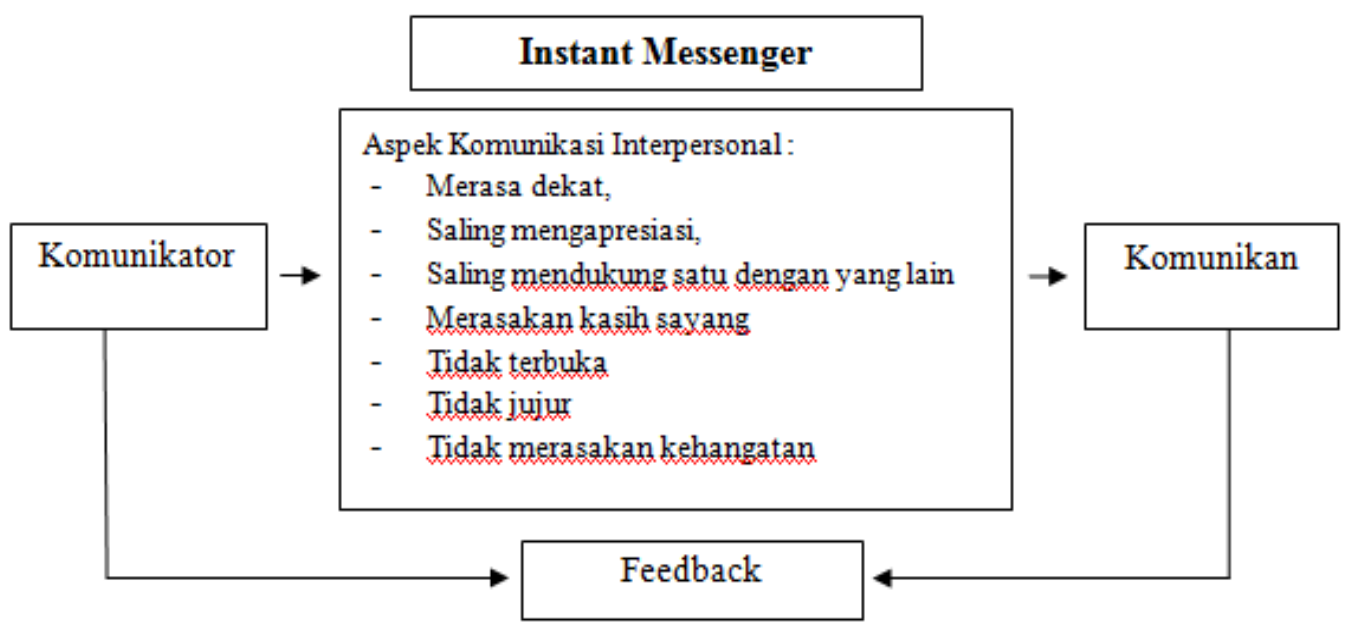

\section{Gambar 5. Komunikasi Interpersonal dengan Keluarga melalui Instant Messenger}

Instant messenger telah menciptakan sebuah ruang virtual dalam berkomunikasi antar personal. Namun pada kenyataannya, media baru meskipun memiliki kemampuan berkomunikasi tanpa mengenal waktu, cepat, dan praktis memiliki kelemahan yaitu mudah terjadi kesalahpahaman atau miscommunication pada saat bertukar informasi. Para informan ketika ditanya dan harus memilih antara komunikasi melalui media siber atau bertatap muka, mereka semua menjawab bahwa komunikasi akan lebih efektif apabila dilakukan secara bertatap muka.

Intimate communication melalui instant messenger sulit tercapai dikarenakan beberapa aspek tidak dapat terpenuhi. Seperti; aspek keterbukaan, kejujuran, kehangatan, dan kedekatan emosional tidak dapat 
terpenuhi oleh komunikasi interpersonal melalui instant messenger. Para informan mengatakan hal - hal tersebut hanya bisa di dapatkan melalui komunikasi tatap muka. Seperti yang diungkapkan oleh Mulyana (2000: 73), komunikasi interpersonal adalah komunikasi antara orang- orang secara tatap-muka, yang memungkinkan setiap pesertanya menangkap reaksi orang lain secara langsung baik secara verbal ataupun secara non verbal.

\section{KESIMPULAN}

Hasil dari penelitian mengenai Penggunaan Instant messenger dan Komunikasi Interpersonal Remaja menghasilkan beberapa kesimpulan, yaitu ;

1. Instant messenger merupakan sebuah medium yang dianggap praktis dan mudah untuk berkomunikasi secara interpersonal dengan keluarga, teman/sahabat, dan kekasih.

2. Emoticon dalam instant messenger merupakan bentuk dari ekspresi yang dirasakan oleh individu (baik komunikan ataupun komunikator).

3. Proses komunikasi interpersonal melalui instant messenger tidak dapat mencapai pada tahap intimate relationship, dikarenakan interaksi yang terjadi sering mengalami miscommunication karena adanya salah persepsi.

4. Komunikasi interpersonal lebih efektif apabila dilakukan dengan bertatap muka. Karena instant messenger tidak mampu mewakili ekspresi, gesture, mimik wajah, dan bahasa non verbal yang terjadi. Meskipun ada emoticon di dalam instant messenger. Saat berkomunikasi melalui instant messenger, remaja cenderung tidak percaya dan berkata tidak jujur pada saat berkomunikasi. 


\section{DAFTAR PUSTAKA}

Beebee, Steven A. Dkk. 2005. Interpersonal Communication Relating To Others. USA: Pearson

Devito, Joseph A. 1996. Human Communication. Alih bahasa oleh Maulana, Agus. 1997. Komunikasi Antar Manusia. Jakarta: Professional Books.

Flew, Terry. 2004. New Media. Oxford, Australia.

Gane, N., \& Beer, D. 2008. New Media, The Key Concepts. New York, Berg.

Griffin, E.M. 2003. A First Look At Communication Theory $5^{\text {th }}$ Edition. McGraw Hill, New York.

Lukman, Enricko. 2014. Laporan 30 Juta Pengguna Internet di Indonesia adalah Remaja.

http://id.techinasia.com/laporan-30-juta-pengguna-internet-di-indonesia-adalah-remaja/ Diakses tanggal 11 Maret 2015.

Morissan, dkk. 2010. Teori Komunikasi Massa. Bogor : Ghalia Indonesia.

Moustakas, Clark. 1994. Phenomenological Research Methods. California : SAGE Publication

Mulyana, Deddy. 2000. Ilmu Komunikasi: Suatu Pengantar. Bandung : PT. Remaja Rosdakarya.

Nasrullah, Rulli. 2015. Media Sosial Prosedur, Tren, dan Etika. Bandung : Simbiosa Rekatama Media.

West, Richard dan Lynn H. Turner. 2007. Introducing Communication Theory. McGraw Hill. New York

Park, Seongwon dkk. 2014. What Makes Smartphone Users Satisfied with Mobile Instant Messenger?: Social Presence, Flow, and Self-disclosure. International Journal of Multimedia and Ubiquitous Engineering Vol. 9, No. 11 (2014), pp. 315-324 http://dx.doi.org/10.14257/ijmue.2014.9.11.31.

Thurlow, C., Lengel L,m \& Tornic, A. 2004. Computer Mediated Communication, Social Interaction and The Internet. Thousand Oaks, CA : SAGE Publication. 